\title{
AS REPRESENTAÇÕES SOCIAIS DO BULLYING DE ACADÊMICOS DO CURSO DE PEDAGOGIA
}

\author{
Karen de Azevedo Coutinho* \\ Solange Franci Raimundo Yaegashi** \\ Luciane Guimarães Batistella Bianchini*** \\ Rute Grossi Milani**** \\ Regiane da Silva Macuch ${ }^{* * * * * *}$
}

RESUMO: O presente estudo teve como objetivo compreender as representações sociais sobre o bullying, compartilhadas pelos acadêmicos do curso de Pedagogia de uma universidade pública do Paraná. Justificamos este estudo pela necessidade de compreender a conceituação do bullying pelos acadêmicos desse curso, futuros professores, visando contribuir com a formação dos novos profissionais da Educação na ampliação de conhecimentos relativos à temática. Como suporte teóricometodológico, foi adotada a Teoria das Representações Sociais (TRS), a qual permite investigar como se forma o funcionamento dos sistemas de referência utilizados para classificar pessoas e grupos e para interpretar os acontecimentos da realidade cotidiana. Participaram do estudo 12 turmas do curso de Pedagogia, totalizando 261 participantes. Além da investigação proposta, baseada num sistema de classificação do método, também foi utilizado o instrumento denominado Teste de Associação Livre de Palavras, para a validação dos objetos representados pela população investigada, com a criação das categorias, via OME (Ordem Média de Evocações) e frequência de evocações (f). Os resultados das duas evocações: "Bullying é" e "Bullying pode levar a vítima a" revelaram que os participantes da pesquisa conceituam bullying ancorando seus conhecimentos sobre o tema na mídia e no senso comum, ou seja, para eles o

\footnotetext{
Mestrado em Educação pela Universidade Estadual de Maringá (UEM). Docente do Ensino Fundamental I na rede particular de ensino e do Instituto Superior de Educação do Paraná (FAINSEP), Brasil.

E-mail: azevedo_karen@yahoo.com.br

* Pós-Doutorado em Psicologia pela Universidade de São Paulo (USP). Docente Associada do Departamento Teoria e Prática da Educação e do Programa de Pós-Graduação em Educação da Universidade Estadual de Maringá (UEM), Brasil.

*** Pós-Doutorado em Psicologia pela Universidade Estadual Paulista (UNESP-Assis). Docente do Programa de Pós-Graduação em Metodologias para o Ensino de Linguagens e suas Tecnologias da UNOPAR, Brasil.

***** Doutorado em Medicina (USP/Ribeirão Preto). Docente Titular no Departamento de Psicologia e nos Programas de Mestrado em Promoção da Saúde e Tecnologias Limpas do Centro Universitário de Maringá. Pesquisadora do Instituto Cesumar de Ciência, Tecnologia e Inovação (ICETI), Maringá (PR), Brasil.

***** Doutorado em Ciências da Educação pela Faculdade de Psicologia e Ciências da Educação da Universidade do Porto, Portugal (FPCEUP) e Pós-Doutorado em Ciências da Educação pela Faculdade de Psicologia e Ciências da Educação da Universidade do Porto, Portugal (FPCEUP). Docente Titular dos Programas de Pós-Graduação Stricto Sensu em Promoção da Saúde e em Gestão do Conhecimentos nas Organizações do Centro Universitário de Maringá (UNICESUMAR), Brasil.
} 
bullying é uma forma de agressão (física, verbal ou moral) que se utiliza de maldade e crueldade com o intuito de desrespeitar, humilhar e excluir outros mais fracos. Foi possível compreender, por meio da identificação das representações sociais dos acadêmicos de Pedagogia que se faz necessária a conscientização/sensibilização dos mesmos, por meio de palestras, Workshops, cursos nas escolas, nas universidades e em centros de apoio à criança, a fim de promover discussões acerca do assunto, de maneira que essas discussões podem estar vinculadas a outras áreas de ensino como Psicologia, Medicina e Enfermagem, já que este fenômeno acarreta prejuízos físicos e psicológicos. Sugere-se, ainda, a realização de trabalhos em grupo (com a finalidade de aproximar os pares), bem como o trabalho com o teatro, por meio do lúdico, pode-se possibilitar à criança expressar simbolicamente o que foi reprimido, expor seus sentimentos, a insegurança, a frustração e a agressividade, permitindo, assim, a conscientização deste ato de violência.

PALAVRAS-CHAVE: Representações Sociais; Senso Comum; Bullying; Saúde escolar; Formação de Professores.

\section{SOCIAL REPRESENTATIONS OF BULLYING BY UNDERGRADUATES OF THE COURSE OF PEDAGOGY}

ABSTRACT: The social representations on bullying by undergraduates of the Course of Pedagogy in a government-run university in the state of Paraná, Brazil, are provided. The concept of bullying by undergraduates, future teachers, is relevant in the training of new professionals in Education so that they could enlarge their knowledge on the theme. The Theory of Social Representations (TSR), as a theoretical and methodological support, helps in investigating the functioning of reference systems used to classify people and groups, and interpret day-to-day events. Twelve groups, totaling 261 participants, participated in the study. Besides the investigation above, the Test of Free Association of Words was also employed to validate objects represented by the population analyzed through the establishment of categories (mean evocation order) and frequency of evocations (f). Results of the two evocations: 'Bullying is...' and 'Bullying may lead the victim to...', demonstrate that participants base their concept of bullying on their knowledge on the theme dealt with in the social media and on common sense. Bully is thus a form of physical, verbal, moral aggression which employs wickedness and cruelty to disrespect, humble and exclude weaker persons. The identification of social representations requires conscience-raising and sensitizing undergraduates through lectures, workshops, courses in schools and universities, and in children's centers. 
Discussions have to be linked to other teaching areas such as Psychology, Medicine and Nursing, since the phenomenon brings about physical and psychological harm. It may be suggested that work groups (approaching partners) and theater (ludic method) may help children to symbolically express their repressions and expose their feelings, insecurity, frustration and aggressiveness. Consequently, conscienceraising of this type of violence will emerge.

KEY WORDS: Social representations; Common sense; Bullying; health in school; Teachers' formation.

\section{INTRODUÇÃO}

O Bullying, frequentemente, é um assunto foco de atenção na mídia e nas instituições de ensino de todos os níveis. Neste sentido, o presente estudo objetiva identificar os elementos que constituem o núcleo central e os elementos periféricos das representações sociais sobre o bullying, compartilhadas pelos acadêmicos do curso de Pedagogia de uma universidade pública do Paraná.

Consideram-se os conhecimentos dos acadêmicos de Pedagogia essenciais nas discussões relativas ao bullying escolar, uma vez que, em pouco tempo, a maioria enfrentará as salas de aula e poderá se deparar com atitudes de bullying e não as perceber. Por isso, as representações que os acadêmicos têm, conscientes ou inconscientes, sobre um determinado conceito, no caso específico desta pesquisa, bullying escolar, influenciam sobremaneira na forma como conduzirão e mediarão as atitudes ligadas a esse fenômeno.

Nesse sentido, acredita-se que o estudo das representações sociais seja um caminho promissor para atingir os propósitos desta pesquisa, à medida que investiga como se formam e como funcionam os sistemas de referência utilizados para classificar pessoas e grupos e para interpretar os acontecimentos da realidade cotidiana. Alves-Mazzotti (2008) assevera que as representações sociais constituem elementos efetivos à análise dos mecanismos que interferem na eficácia do processo educativo, uma vez que mantêm relações com a linguagem, com a ideologia e com o imaginário social e por seu papel de orientação de condutas e das práticas sociais.

Os estudos acerca do bullying revelam que este fenômeno é capaz de acarretar enorme prejuízo emocional, psicológico e social ao indivíduo e pode 
também comprometer o processo de aprendizagem (PEREIRA, 2002; CONSTANTINI, 2004; FANTE, 2005; LOPES NETO, 2005; BEAUDOIN; TAYLOR, 2006; LEMOS, 2007; FANTE; PEDRA 2008; ANTUNES, 2010; BINSFELD; LISBOA, 2010; COUTINHO, 2013; SARZI, 2013; ALMEIDA; LISBOA, 2014; COUTINHO, 2017).

$\mathrm{Na}$ acepção de Weiss (1997), o aprendizado envolve aspectos orgânicos, sociais, cognitivos e emocionais. O não-aprender pode estar ligado a uma dificuldade na relação da criança com a própria família, ou a uma dificuldade ou problemas com os colegas, ou a uma vitimização de bullying.

É necessário que os futuros professores abordem o bullying, as características, as formas de envolvimento e suas causas, para que consigam identificar e combater esse tipo de fenômeno que assola muitas crianças e adolescentes, impedindo-os de terem um desenvolvimento saudável.

Entende-se que o tema é de grande relevância para a Educação, uma vez que o bullying ocorre, na maioria das vezes, dentro das escolas. Por esse motivo, a pesquisa foi realizada com acadêmicos do curso de Pedagogia, os quais foram considerados indivíduos sociais que compartilham, com seu grupo, pensamentos e atitudes, ou seja, suas representações sociais. Além disso, essa temática é relevante também para os gestores, docentes, psicólogos escolares e demais servidores que atuam diretamente na escola, visando contribuir para melhor compreensão do assunto.

\section{BULLYING}

Bullying é uma palavra de origem inglesa, utilizada em vários países para definir "o desejo consciente e deliberado de maltratar uma pessoa e colocá-la sob tensão" (TATUM; HERBERT, 1999 apud FANTE; PEDRA, 2008, p. 32). É um termo empregado na literatura anglo-saxônica para designar comportamentos agressivos e antissociais entre escolares (FANTE; PEDRA, 2008).

O bullying difere de uma brincadeira inocente, que não tem intenção de ferir, pois se caracteriza por atitudes hostis, que violam o direito à integridade física e psicológica das vítimas; ameaça o direito à educação, ao desenvolvimento, à saúde e à sobrevivência de muitas vítimas que se sentem indefesas, vulneráveis, com medo 
e vergonha, o que favorece o rebaixamento da autoestima da pessoa e a vitimização continuada e crônica (FANTE; PEDRA, 2008).

Antunes (2010) ressalta que a palavra bullying deixou de ser um termo com significado cotidiano dos dicionários, encontrado como "maltratar/intimidar" e passou a representar um conceito utilizado pela comunidade científica para se referir a determinadas relações de violência, físicas ou psicológicas, entre colegas em diferentes ambientes e contextos, inclusive o escolar.

O pesquisador Dan Olweus estabelece critérios para a identificação do comportamento bullying, a fim de o diferenciar de outras formas de violência e das brincadeiras próprias da idade: "Os critérios estabelecidos são: ações repetitivas contra a mesma vítima num período prolongado de tempo; desequilíbrio de poder, o que dificulta a defesa da vítima; ausência de motivos que justifiquem os ataques" (FANTE; PEDRA, 2008, p. 39).

O desequilíbrio de poder associado ao bullying pode resultar da diferença de idade, tamanho, desenvolvimento físico ou emocional, ou do maior apoio dos demais estudantes. Pereira (2002) relata que o bullying comumente é praticado contra os mais inseguros, mais fáceis de atemorizar ou que têm maior dificuldade em se defender ou pedir ajuda.

Constantini (2004) sustenta que as atitudes de bullying não são os conflitos normais ou as brigas que acontecem entre estudantes, mas atos de intimidação préestabelecidos, ameaças que se utilizam de violência física e psicológica impostas repetidamente a indivíduos mais frágeis e incapazes de se defender, o que os leva a uma condição de sujeição, sofrimento psicológico, isolamento e marginalização. A natureza repetitiva do bullying ocorre em consequência de uma mesma pessoa ser alvo de agressão diversas vezes e de não conseguir se defender de maneira eficaz para conseguir interrompê-la (ANTUNES, 2010).

Os comportamentos incluídos no bullying são vários, citamos alguns como: "apelidar, ofender, 'zoar', 'sacanear', humilhar, intimidar, 'encarnar', constranger, discriminar, aterrorizar, amedrontar, tiranizar, excluir, isolar, ignorar, perseguir, chantagear, assediar, ameaçar, difamar, insinuar, agredir, bater, chutar, empurrar, derrubar, ferir, esconder, quebrar, furtar e roubar pertences" (FANTE; PEDRA, 2008, p. 36, grifos dos autores) e ainda "sexualizar ou fazer ofensas étnicas ou de gênero" 
(MIDDELTON-MOZ; ZAWADSKI, 2007, p. 14, grifo das autoras). Também infligir ou incomodar o outro por meio de palavras, ações, contato físico, caretas e gestos obscenos (ANTUNES, 2010).

Quando submetidas ao bullying em longo prazo, as vítimas podem encontrar como única saída atitudes agressivas contra si mesmas e contra os outros. Isso representa uma ameaça não só para a vítima, mas também para a sociedade (LYRA; BAUMER, 2011), uma vez que massacres em escolas, de acordo com a mídia, envolvem pessoas vitimizadas.

As consequências desse tipo de violência são negativas, imediatas e duradouras a todos os envolvidos: agressores, vítimas e observadores. Para as vítimas, esses danos podem ser extremamente prejudiciais, pois elas tendem a exibir um autoconceito geralmente desfavorável: baixa autoestima, problemas de saúde física (sintomas psicossomáticos) e de saúde mental (sintomas depressivos, insegurança e ansiedade); tendem, ainda, a problemas acadêmicos e à evasão escolar.

\section{REPRESENTAÇÕES SOCIAIS}

A noção da Teoria das Representações Sociais (TRS), tal como é entendida no presente estudo, foi introduzida por Serge Moscovici, em 1961, na obra " $L a$ Psychanalyse, son image, son public", na qual o autor estuda a representação social da psicanálise, na França.

Ao estudar as representações sociais (RS), estuda-se a forma como um grupo constrói seus saberes socialmente partilhados. Esses saberes, frisa Jovchelovitch (1998), conseguem expressar, de uma só vez, a identidade de um grupo social, as representações que este mesmo grupo detém sobre diversos objetos tanto próximos como longínquos e, sobretudo, o conjunto dos códigos culturais que definem em cada momento histórico o modo de vida de uma comunidade.

Acentua-se que as representações sociais é resultado das interações sociais e do ambiente simbólico em que estão imersas como as crenças, os valores, os conhecimentos científicos e o senso comum. Não são cópias do mundo exterior, mas construções dos atores sociais e expressam a complexidade das interações entre os 
mundos interno e externo, entre os sujeitos e as coletividades (JOVCHELOVITCH, 2011).

Na visão de Moscovici (2012), as representações sociais reúnem experiências, vocabulários, conceitos e reduzem os aspectos separados do real. Representar não é reproduzir a realidade, mas transformá-la, de forma que conceito e percepção se unam, criando a impressão de que o conceito é a própria realidade.

Ao sistematizar a teoria das representações sociais, Moscovici (1961) reabilita o senso comum, não mais como um conhecimento confuso, inconsistente, equivocado, mas como um conhecimento válido que nasce das relações sociais (JODELET, 1984).

Abric (1998) pontua que toda representação é uma forma de visão global de um objeto, mas também de um sujeito, que reorganiza a realidade e, assim, permite a associação das características objetivas do objeto, das experiências anteriores do sujeito e do seu sistema de atitudes e normas. Isso permite, de acordo com o autor, definir a representação como:

[...] uma visão funcional do mundo, que, por sua vez, permite ao indivíduo ou ao seu grupo dar um sentido às suas condutas e compreender a realidade através de seu próprio sistema de referências, permitindo assim ao indivíduo de se adaptar e de encontrar um lugar nessa realidade (ABRIC, 1998, p. 28).

Por meio das representações, os sujeitos se sentem pertencentes ou não a determinado grupo, pensam e agem de certa maneira e não de outra. Spink (1993) propala que a representação é uma construção do sujeito enquanto sujeito social, uma vez que este não é apenas produto de determinações sociais, nem produtor independente. As representações são, portanto, construções contextualizadas, resultados das condições em que surgem e circulam.

As representações sociais referem-se tanto a uma teoria quanto a um fenômeno que proporciona um conjunto de conceitos articulados que procuram explicar como os saberes sociais são produzidos e transformados em processos de comunicação e interação social. Elas são um fenômeno que se refere a um conjunto de regularidades empíricas e que abrangem as ideias, os valores e as práticas de comunidades humanas sobre objetos sociais específicos, bem como sobre processos sociais e comunicativos que produzem e reproduzem (JOVCHELOVITCH, 2011). 
Jodelet (1984), por sua vez, assinala que, enquanto fenômeno, as representações sociais são apresentadas por vários tipos, entre eles:

Imagens que condensam um conjunto de significados; sistemas de referência que nos permitem interpretar o que nos acontece, e até mesmo dar um sentido ao inesperado; categorias que servem para classificar as circunstâncias, os fenômenos e os indivíduos com quem temos algo que fazer; teorias que estabelecem fatos sobre eles. E, muitas vezes, quando eles são entendidos dentro da realidade concreta de nossa vida social, as representações sociais são todos eles juntos (JODELET, 1984, p. 472).

Jovchelovitch (2013) assinala que as representações sociais é uma estratégia desenvolvida por atores sociais para enfrentar a diversidade e a mobilidade de um mundo que, mesmo pertencendo a todos, sobrepuja cada um individualmente. Elas são, segundo a autora, espaço de fabricação comum, em que cada sujeito ultrapassa sua individualidade para entrar em um domínio diferente, porém relacionado, isto é, para entrar no domínio da vida em comum, o espaço público.

As representações sociais surgem por meio de mediações sociais e tornam-se, elas próprias, mediações sociais e expressam o espaço do sujeito na relação com sua singularidade, lutando para interpretar, entender e construir o mundo.

A formação das representações de um objeto ocorre constantemente na interação entre indivíduos sociais, em dois processos que estão interligados: a objetivação e a ancoragem. A primeira permite tornar real um esquema conceitual e substituir uma imagem por algo "material"; já a segunda é o ato de comparar algo que não conhecemos com algo qua já conhecemos, ou seja, tornar familiar o não familiar, e para isso utilizamos nosso sistema de conhecimentos, nosso senso comum (CARDOSO, 2012; MOSCOVICI, 2015).

Jovchelovitch (2011) ressalta que objetivação e ancoragem são as formas específicas em que as representações sociais estabelecem mediações. Elas trazem quase para um nível material a produção simbólica de uma comunidade e dão veracidade às representações sociais na vida social.

Segundo Abric (1998), as representações sociais são um conjunto de crenças, de opiniões e de atitudes a propósito de dado objeto social. Quando organizado, esse conjunto de elementos estrutura-se e constitui um sistema sociocognitivo de 
tipo específico; essa hipótese foi chamada pelo autor de núcleo central e formulada nesses termos:

[...] a organização de uma representação apresenta uma modalidade particular, específica: não somente os elementos da representação são hierarquizados, mas também toda representação está organizada ao redor de um núcleo central constituído por um ou vários elementos que dão significação à representação (ABRIC, 2001, p. 18).

O núcleo central tem outra propriedade que deve ser ressaltada, o elemento, ou elementos, mais estáveis da representação, ou seja, aquele que assegura a continuidade em contextos móveis e evolutivos. É o elemento dentro de uma representação que mais resiste à mudança. Assim, qualquer modificação do núcleo central promove transformação completa da representação (ABRIC, 1998).

O núcleo central é, ainda, segundo Abric (1998; 1994, apud SÁ, 2002), marcado pela memória coletiva e pelo sistema de norma ao qual se refere, é a base comum, compartilhada coletivamente, de uma representação social cuja função é consensual; é por meio dele que se define a homogeneidade de um grupo social, além de manter a estabilidade e a coerência da representação, assegurando a perenidade e a manutenção no tempo.

Ao redor do núcleo central, conforme Abric (1998; 2001), organizamse os elementos periféricos que estão em relação direta com ele, ou seja, sua presença, sua avaliação, seu valor e sua função são determinados pelo núcleo. Estes constituem o essencial do conteúdo da representação, seu lado mais acessível, mas também o mais vivo e concreto. Para Sá (2002), o sistema periférico atualiza e contextualiza continuamente as condições normativas e consensuais, conferindo aos elementos periféricos a mobilidade, a flexibilidade e a expressão individualizada que caracterizam as representações sociais.

Assim, por meio da Teoria do Núcleo Central (TNC), proposta por Abric (1998), podemos compreender como os significados se organizam em um determinado grupo (acadêmicos) e verificar até que ponto essas representações guiam a compreensão dos indivíduos, o que constitui, em nosso entendimento, uma possibilidade de leitura de questões que envolvem o bullying escolar. 


\section{PROCEDIMENTOS METODOLÓGICOS}

Esta pesquisa foi realizada com acadêmicos do curso de Pedagogia de uma universidade pública, localizada no Norte do Paraná cuja cidade, segundo os dados do IBGE (2014), possui população estimada de 391.698 habitantes.

Com base nos dados fornecidos pela universidade, o curso de Pedagogia tem 443 acadêmicos matriculados; destes, oito estavam com a matrícula do ano de 2015 trancada, totalizando 435 acadêmicos em curso no momento da pesquisa. As turmas são separadas por turnos: matutino (uma turma de $1^{\circ}$ ao $4^{\circ}$ ano, totalizando 4 turmas) e noturno (duas turmas de $1^{\mathrm{o}}$ ao $4^{\mathrm{o}}$ ano, totalizando 8 turmas).

Participaram deste estudo 261 acadêmicos, o que representa $60 \%$ dos alunos matriculados no curso de Pedagogia da universidade referida. Esse número refere-se ao fato de aplicarmos os questionários no início das aulas, sendo que muitos alunos ainda não estavam presentes. Os alunos presentes foram convidados a participar da pesquisa e apenas dois recusaram-se. A coleta de dados ocorreu em fevereiro de 2016.

A maioria dos participantes cursava o primeiro ano de Pedagogia (29,89\%); seguida pelo terceiro ano (26,44\%), segundo ano (23,37\%) e quarto ano $(20,31 \%)$. Podemos inferir que isso aconteceu devido à desistência dos acadêmicos no decorrer do curso de graduação. No entanto, entende-se também que, devido à pesquisa ter sido realizada no final do semestre, muitos acadêmicos do $4^{0}$ ano estavam se preparando para a defesa de TCC, o que acarretou maior número de faltas durante o período de realização da pesquisa.

No que diz respeito ao período, a grande maioria $(68,20 \%)$ frequentava o período noturno, uma vez que há oito turmas neste período e apenas quatro no período matutino.

Para identificar as representações sociais dos acadêmicos de Pedagogia acerca de bullying escolar, foi adotado como instrumento o Teste de Associação Livre de Palavras (TALP) cujo objetivo consiste na identificação dos elementos nucleares e periféricos da representação (MENIN; SHIMIZU; LIMA, 2009).

As palavras evocadas no TALP foram analisadas, segundo critérios apontados por Sá (1998), Naiff, Naiff e Souza (2009), Magalhães Júnior e Tomanik (2012, 2013), Oliveira et. al. (2010) e Cortes Junior (2008). 
Entretanto, é válido ressaltar que, ao serem apresentados os termos indutores, não foi solicitada, aos participantes, uma quantidade determinada de palavras; assim somente foram analisadas as respostas dos sujeitos que evocaram três ou mais palavras; deste modo, o número de participantes difere do número total de participantes da pesquisa (sempre menor).

Também não foi solicitado que os participantes hierarquizassem as palavras e as expressões evocadas por grau de importância; assim, as palavras foram hierarquizadas, seguindo-se a ordem em que apareceram, sendo a primeira considerada a mais importante, por ter sido prontamente evocada (1) e assim sucessivamente.

Partindo da fórmula proposta e adaptada por Magalhães Júnior e Tomanik $(2012)^{6}$, bem como das expressões apresentadas por Cortes Junior (2008) ${ }^{7}$, determinamos a Ordem Média de Evocações (OME) e a Frequência Média das Evocações; após esta etapa, organizamos as palavras em um quadro, com quatro quadrantes, considerando-se os critérios de saliência e de importância, observados por meio da frequência e da ordem das evocações produzidas. Desta maneira, foi possível apreender quais elementos das representações sociais estavam presentes de forma mais central no discurso cotidiano dos sujeitos acerca do tema estudado.

Cortes Junior e Fernandez (2016) salientam que a frequência representa a quantidade de vezes que a mesma palavra aparece nas evocações; e a ordem média de evocação (OME) representa o posicionamento que a mesma palavra ocupa dentro das três evocações. Quanto menor a OME, mais espontaneamente ela foi evocada, e, portanto, constitui-se mais possivelmente como participante do núcleo central.

Cortes Junior (2008) enfatiza que, ao se considerar tanto a frequência quanto o OME, dois critérios metodológicos são criados: um, de natureza coletiva, representado pela frequência com que a categoria é evocada pelo conjunto dos sujeitos; e o outro, de natureza individual, dado pela ordem que cada um confere à categoria no conjunto de suas próprias evocações.

6 Ordem Média de Evocação $=\sum_{1}^{n} P . G$ Somatório $(\Sigma)$ do número de vezes que a palavra foi evocada (P), numa dada posição de grau de importância, vezes seu grau de importância $(G)$, dividido pela frequência com que a palavra foi evocada no total (MAGALHÃES JÚNIOR, TOMANIK, 2012).

$\mathrm{f}$ média $=\frac{f \text { total }}{\text { némero de palayras }}$ OME média $=\frac{\text { OME total }}{\text { numera de palayras }}$ (CORTES JUNIOR, 2008, p. 52). 
Oliveira et. al. (2010) e Naiff, Naiff e Souza (2009) corroboram quanto à distribuição dos termos nos quadrantes, ao enfatizarem que estes obedecem a alguns critérios, também seguidos nesta pesquisa, são eles: no primeiro quadrante (superior esquerdo), estão os termos que se destacaram em relação à frequência e à ordem de evocações, formando o provável núcleo central da representação; no segundo quadrante (superior direito), os termos que apresentam alta frequência, mas que foram tardiamente evocados, formando a primeira periferia composta pelos elementos periféricos mais importantes da representação; no terceiro quadrante (inferior esquerdo), denominado elementos de contraste, aqueles que atenderam ao critério de importância, mas não de saliência, ou seja, foram considerados importantes pelos sujeitos, mas apresentaram baixa frequência. No quarto quadrante (inferior direito), os termos que apresentaram baixa frequência e foram tardiamente evocados constituem os elementos periféricos da representação.

Essa pesquisa foi aprovada pelo Comitê Permanente de Ética em Pesquisa envolvendo Seres Humanos (COPEP) da UEM, parecer consubstanciado ${ }^{0}$ 1.407.697, e todos os participantes da pesquisa assinaram o Termo de Consentimento Livre e Esclarecido.

\section{RESULTADOS E DISCUSSÕES}

Inicialmente, para a análise do Teste de Associação Livre de Palavras, as palavras/expressões foram separadas por grupos semânticos, ou seja, as palavras que apresentavam o mesmo sentido. Assim, as palavras foram colocadas em tabelas, juntamente com um número que variava de 1 a 3 , que designava seu grau de importância. A partir dessas tabelas, encontrou-se a frequência média e a Ordem Média de Evocação (OME) para determinar o núcleo central e periférico das representações sociais dos acadêmicos acerca de bullying.

Conforme Vergès (1992, apud SÁ, 2002), os prováveis elementos que constituem o núcleo central são avaliados pelo número de vezes que aparecem nas evocações e por serem mais prontamente evocados. Assim, a natureza coletiva da representação é evidenciada pela frequência com que a palavra/expressão é adotada, 
e a natureza individual é dada pela ordem que cada sujeito confere à categoria no conjunto de suas próprias evocações; esse índice é associado aos demais sujeitos no cálculo de uma ordem média de evocação.

Sá (2002) pontua que os grupos semânticos que atendem simultaneamente à natureza coletiva e individual estão situados no quadrante superior esquerdo do quadro, pois apresentam frequências de evocação acima da frequência média do conjunto de categorias e ordens médias de evocação abaixo da média das ordens médias das diferentes categorias.

\subsection{EVOCAÇÃO 1: (BULLYING É)}

$\mathrm{Na}$ análise das evocações do termo indutor "Bullying é", foram registrados 180 palavras/expressões evocadas, das quais foram descartadas as que tiveram frequência igual a um, conforme sugerem Magalhães Junior e Tomanik (2012), pois só é considerada como representação aquilo que é partilhado por um grupo, ficando para análise desta pesquisa 169 palavras/expressões. Foram excluídas do quadro as palavras: triste, tirar sarro, ruim, competição, insegurança, invasão de privacidade, fragilidade, falta de noção, terrorismo, gestos, irritar. Em seguida, as palavras que apresentavam o mesmo sentido foram reunidas em grupos semânticos, formando 13 grupos.

A partir da análise combinada da frequência e da ordem média de evocação de cada grupo, levantou-se os elementos supostamente pertencentes ao núcleo central e elementos periféricos da representação social da pergunta indutora "Bullying é". Com esse termo, procurou-se apreender o conceito que os acadêmicos têm acerca do objeto desse estudo. A média das ordens médias (OME) foi de 2,10 e a média de frequência (f) foi de 13,00. O Quadro 1 apresenta a análise das palavras e mostra os quatro quadrantes com os possíveis grupos que compõem as RS. 
Quadro 1. Palavras evocadas pelos acadêmicos do curso de Pedagogia referente a 'Bullying é'

\begin{tabular}{|c|c|c|c|c|c|}
\hline \multicolumn{3}{|c|}{$\begin{array}{l}\text { Elementos Centrais - } \\
1^{\circ} \text { quadrante }\end{array}$} & \multicolumn{3}{|c|}{$\begin{array}{l}\text { Elementos Intermediários - } \\
2^{\circ} \text { quadrante }\end{array}$} \\
\hline \multicolumn{3}{|c|}{$\begin{array}{l}\text { Alta f e baixa Ordem Média de Evocações } \\
\qquad \mathrm{f}>13,00 \text { e } \mathrm{OME}<2,10\end{array}$} & \multicolumn{3}{|c|}{$\begin{array}{l}\text { Alta F e alta Ordem Média de Evocações } \\
\qquad f>13,00 \text { e } \mathrm{OME} \geq 2,10\end{array}$} \\
\hline Palavra & Freq. & OME & Palavra & Freq. & OME \\
\hline $\begin{array}{l}\text { Agressão Verbal } \\
\text { Agressão Física } \\
\text { Desrespeito } \\
\text { Humilhação/ } \\
\text { Constrangimento }\end{array}$ & $\begin{array}{l}28 \\
20 \\
18 \\
13\end{array}$ & $\begin{array}{l}1,64 \\
1,75 \\
1,67 \\
2,08\end{array}$ & $\begin{array}{c}\text { Agressão/ } \\
\text { Violência } \\
\text { Agressão Moral } \\
\text { Preconceito }\end{array}$ & $\begin{array}{l}17 \\
13\end{array}$ & $\begin{array}{l}2,22 \\
2,23 \\
2,38\end{array}$ \\
\hline \multicolumn{3}{|c|}{ Elementos Intermediários - $3^{\circ}$ quadrante } & \multicolumn{3}{|c|}{ Elementos Periféricos - $4^{\circ}$ quadrante } \\
\hline \multicolumn{3}{|c|}{$\begin{array}{l}\text { Baixa F e baixa Ordem Média de Evocações } \\
\qquad \mathrm{f}<13,00 \text { e } \mathrm{OME}<2,10\end{array}$} & \multicolumn{3}{|c|}{$\begin{array}{l}\text { Baixa F e alta Ordem Média de Evocações } \\
\qquad \mathrm{f}<13,00 \text { e } \mathrm{OME} \geq 2,10\end{array}$} \\
\hline Palavra & Freq. & OME & Palavra & Freq. & OME \\
\hline $\begin{array}{l}\text { Exclusão } \\
\text { Brincadeira }\end{array}$ & $\begin{array}{l}4 \\
2\end{array}$ & $\begin{array}{l}1,50 \\
2,00\end{array}$ & $\begin{array}{c}\text { Crueldade/ } \\
\text { Maldade } \\
\text { Sem consciência } \\
\text { Crime } \\
\text { Fragilidade }\end{array}$ & $\begin{array}{l}12 \\
2 \\
2 \\
2\end{array}$ & $\begin{array}{l}2,17 \\
2,33 \\
2,50 \\
2,50\end{array}$ \\
\hline
\end{tabular}

Fonte: Elaborado pelos autores.

No Quadro 1, percebe-se, no quadrante superior esquerdo, os quatro grupos de palavras que possivelmente representam os elementos centrais das RS, por serem mais frequentes e prontamente evocados (SÁ, 1998). Ao agrupar semanticamente as palavras, foram subdivididos os vários tipos de agressão evocados em 'Agressão Verbal', incluindo xingamentos, apelidos, piadas e ofensas, que apresentaram frequência de 28 e uma OME de 1,64; 'Agressão Física', com frequência de 20 e OME de 1,75, ambos fazendo parte do primeiro quadrante, ou seja, do núcleo central.

As agressões verbais apresentam alta frequência, porque a maioria dos participantes deste estudo é do gênero feminino, e os tipos de bullying mais praticados ou sofridos por elas, em período escolar, segundo Fante e Pedra (2008), são as fofocas, a difamação, a manipulação, as ofensas verbais quanto ao corpo e a 
exclusão. Estes autores ressaltam que os ataques praticados por meninas geralmente acontecem em um círculo restrito de amizades, o que torna a agressão mais difícil de ser identificada, reforçando os danos causados às suas vítimas.

Destaca-se, ainda, que muitas investigações (FANTE, 2005; LOPES NETO, 2005; FANTE; PEDRA, 2008, LISBOA; BRAGA; EBERT, 2009) foram realizadas pelos pesquisadores dessa área de conhecimento, o que permite afirmar que colocar apelidos é o tipo mais comum de agressão de bullying. A prática de colocar apelidos está relacionada especificamente à existência de preconceitos que envolvem todo tipo de questão como as étnico-raciais, as deficiências físicas e mentais, a orientação sexual, e incluem a aparência corporal e os atos pessoais (ENZ; EYNG; GISI, 2013).

'Agressão/Violência', apesar de apresentar frequência 36 (o que obteve maior quantidade de evocações), não foi considerado como elemento do núcleo central, pois seu OME foi maior que 2,10 (2,22); 'Agressão Moral', que inclui intimidação, perseguição, coação e ameaças, teve frequência de 17 e OME de 2,23, também sendo excluído do núcleo central.

A violência apresenta-se no imaginário e no cotidiano social; ela está presente nos filmes, nas novelas, nos noticiários, nos jornais, nas revistas e na Internet. Conforme Minayo (1994), não há conhecimento de nenhuma sociedade onde não haja violência, pois a violência é um dos infindáveis problemas da teoria social e da prática política e relacional da humanidade.

No entanto, não se podem confundir atos pontuais de violência com bullying, visto que o primeiro pode ocorrer no calor de uma discussão, por motivos passionais, discordâncias política, religiosas, entre outros. Já, no bullying, a violência é velada, não há motivos aparentes, ela pode ser direta (física) ou indireta (boatos, xingamentos, difamação).

Também para se caracterizar como bullying, os atos devem ser repetitivos e representar desigualdade de poder. Ao apresentar uma frequência tão alta e um grau de importância menos relevante, entende-se que ainda há dificuldade entre os acadêmicos em distinguir atos de violência e bullying.

Ainda fazem parte do possível núcleo central o grupo 'Desrespeito' e 'Humilhação/Constrangimento', com frequências de 18 e 13 e OME de 1,67 e 2,08, respectivamente.

Pullin e Pryjma (2011) declaram que o sistema periférico é um 
complemento indispensável do núcleo central, pois protege, atualiza e contextualiza constantemente suas determinações normativas, permitindo aos sujeitos uma flexibilidade e adequação em função de suas experiências cotidianas. Sendo assim, neste estudo, será apresentada também a leitura dos demais quadrantes.

O segundo e o terceiro quadrantes, considerados elementos intermediários, apresentam a palavra/expressão 'Preconceito', que compreende o racismo, os julgamentos, o machismo e a intolerância, com frequência de 13 e OME de 2,38; as outras duas do segundo quadrante já foram expostas: 'Exclusão', com frequência 4 e OME de 1,50; e 'Brincadeira', com frequência 2 e OME de 2,00. Estas últimas evocações demonstram que ainda há pessoas que consideram o bullying uma brincadeira e não um tipo de violência que se apresenta de forma velada, cuja capacidade de destruição ao psiquismo dos envolvidos é grande.

Os elementos periféricos que aparecem no quarto quadrante são compostos pelas palavras/expressões mais tardiamente evocadas e que apresentam frequência menor que a frequência média $(13,00)$ e OME maior ou igual ao OME médio $(2,10)$, são elas: 'Crueldade/Maldade', com frequência 12 e OME 2,17; 'Sem consciência', que diz respeito à falta de consciência das pessoas acerca do outro, com frequência e e OME 2,33; 'Crime' e 'Fragilidade' (possivelmente relacionadas à vítima), ambas com frequência 2 e OME de 2,50.

Ao se analisar o quadro de quatro quadrantes como um todo, percebeuse que algumas palavras/evocações como desrespeito, maldade, crueldade, falta de consciência, preconceito, podem estar vinculadas ao ideal de moral e ética, ou melhor, à falta de ética (crise) em que nossa sociedade está imersa. As causas que motivam a crise ética podem estar pautadas nas transformações estruturais que começaram a modificar a visão de mundo do homem ocidental. Valores essenciais estão desaparecendo do nosso universo simbólico, e assim o mundo em que vivemos se tem tornado cada vez mais violento, e a violência se alastra em todos os setores da vida social,

[...] nas famílias (filhos planejam friamente o assassinato de seus pais), nas escolas (adolescentes matam seus professores e colegas), nos campos (agricultores e camponeses agridem-se e se matam) e nas cidades (os assaltos, sequestros e crimes são tão frequentes e corriqueiros que já estamos nos habituando a olhá-los, para dizê-lo 
com Hannah Arendt, como uma verdadeira "banalização do mal") (ROCHA, 2007, p. 127).

Assim, assevera-se que a violência, que tem aumentado consideravelmente em nossa sociedade, até mesmo entre crianças e adolescentes, como o bullying, é consequência da visão de mundo na qual os valores éticos estão sendo descartados, dando lugar ao poder econômico, priorizando o ter sobre o ser.

A partir da configuração dos quatro quadrantes, apreende-se que os acadêmicos do curso de Pedagogia analisados definem bullying como uma forma de agressão (física, verbal ou moral), e que seu autor se utiliza de maldade e crueldade com o intuito de desrespeitar, humilhar e excluir.

\subsection{EVOCAÇÃO 2: (BULLYING PODE LEVAR A VÍTIMA A)}

A segunda pergunta evocadora foi "Bullying pode levar a vítima a", com a qual se pretendeu depreender as prováveis representações sociais dos participantes acerca das consequências desse fenômeno para as vítimas.

Foram evocadas 241 palavras/expressões. As palavras que tinham o mesmo sentido foram reunidas em grupos semânticos, formando 17 grupos; no entanto, foram excluídas três palavras/expressões por apresentar frequência igual a um e não se encaixar em nenhum grupo, são elas: feia, tímida, incapaz.

Optou-se por nomear os grupos semânticos não utilizando a palavra de maior frequência, como sugerem Oliveira et al. (2010), mas por tipos de transtornos, uma vez que muitos foram os transtornos evocados como estresse, ansiedade, tensão, medo, raiva, irritabilidade, dificuldade de concentração, déficit de atenção, angústia, tristeza, desgosto, apatia, cansaço, insegurança, sentimento de abandono e de inferioridade, mágoa, desejo de vingança e pensamentos suicidas, depressão, fobias e hiperatividade, entre outros. Assim, foi elaborado o Quadro 2, no qual se apresentam os quatro quadrantes. 
Quadro 2. Palavras evocadas pelos acadêmicos do curso de Pedagogia referente a Bullying pode levar a vítima a

\begin{tabular}{|c|c|c|c|c|c|}
\hline \multicolumn{3}{|c|}{$\begin{array}{l}\text { Elementos Centrais - } \\
1^{\circ} \text { quadrante }\end{array}$} & \multicolumn{3}{|c|}{$\begin{array}{l}\text { Elementos Intermediários - } \\
\qquad 2^{\circ} \text { quadrante }\end{array}$} \\
\hline \multicolumn{3}{|c|}{$\begin{array}{l}\text { Alta f e baixa Ordem Média de Evocações } \\
\qquad \mathrm{f}>14,00 \text { e } \mathrm{OME}<2,01\end{array}$} & \multicolumn{3}{|c|}{$\begin{array}{l}\text { Alta F e alta Ordem Média de Evocações } \\
\qquad \mathrm{f}>14,00 \text { e } \mathrm{OME} \geq 2,01\end{array}$} \\
\hline Palavra & Freq. & OME & Palavra & Freq. & OME \\
\hline $\begin{array}{l}\text { Transtornos de humor } \\
\text { Morte } \\
\text { Desvalorização pessoal }\end{array}$ & $\begin{array}{l}62 \\
29 \\
21\end{array}$ & $\begin{array}{l}1,35 \\
1,75 \\
1,76\end{array}$ & $\begin{array}{l}\text { Isolamento } \\
\text { Transtornos de } \\
\text { ansiedade }\end{array}$ & $\begin{array}{l}34 \\
25\end{array}$ & $\begin{array}{l}2,02 \\
2,32\end{array}$ \\
\hline \multicolumn{3}{|c|}{ Elementos Intermediários - $3^{\circ}$ quadrante } & \multicolumn{3}{|c|}{ Elementos Periféricos $-4^{\circ}$ quadrante } \\
\hline \multicolumn{3}{|c|}{$\begin{array}{l}\text { Baixa F e baixa Ordem Média de Evocações } \\
\qquad \mathrm{f}<14,00 \text { e } \mathrm{OME}<2,01\end{array}$} & \multicolumn{3}{|c|}{$\begin{array}{l}\text { Baixa F e alta Ordem Média de Evocações } \\
\qquad \mathrm{f}<14,00 \text { e } \mathrm{OME} \geq 2,01\end{array}$} \\
\hline Palavra & Freq. & OME & Palavra & Freq. & OME \\
\hline $\begin{array}{l}\text { Transtornos psicológicos } \\
\text { Problemas escolares } \\
\text { Agressividade } \\
\text { Inferioridade / } \\
\text { Insegurança } \\
\text { Insatisfação } \\
\text { Exclusão } \\
\text { Solidão }\end{array}$ & $\begin{array}{l}4 \\
3 \\
2\end{array}$ & $\begin{array}{l}2,00 \\
2,00 \\
2,00\end{array}$ & $\begin{array}{c}\text { Tristeza } \\
\text { Vergonha } \\
\text { Doenças } \\
\text { Transtornos } \\
\text { alimentares } \\
\text { Uso de substâncias }\end{array}$ & $\begin{array}{l}12 \\
7 \\
5 \\
4\end{array}$ & $\begin{array}{l}2,08 \\
2,42 \\
2,40 \\
2,75\end{array}$ \\
\hline
\end{tabular}

Fonte: Elaborado pelos autores.

Fazem parte do possível núcleo central ( $1^{\circ}$ quadrante), os 'Transtornos de humor' como a depressão (frequentemente evocada), a irritabilidade, o desânimo, o mau humor e a frustração. Este grupo apresentou frequência de 62, significativamente maior em relação aos outros grupos e uma OME de 1,35, que caracteriza acentuadamente o grau de importância dado a esse tipo de transtorno pelos participantes da pesquisa.

Também fazem parte do núcleo central (NC) o grupo denominado 'Morte', que inclui o suicídio e o assassinato, o qual apresentou frequência de 29 e OME de 1,75 , o que sugere que a RS das consequências de bullying podem estar vinculadas aos massacres em escolas, cinemas, entre outros noticiados na televisão, apresentando 
os autores como possíveis vítimas de bullying. Por fim, a 'Desvalorização' pessoal que abarca a baixa autoestima, a depreciação, o sentimento de incapacidade, de menosprezo, que obteve frequência de 21 e OME de 1,76.

Conforme Middelton-Moz e Zawadski (2007), ser alvo de bullying causa intensos sentimentos de medo e vergonha, aumenta a vulnerabilidade, baixa a autoestima e leva à ansiedade, à depressão e a sensações de impotência que fazem com que a vitimização aumente. Para os autores, "Infelizmente, as vítimas se culpam pelo comportamento do bully e, muitas vezes outros também culpam a vítima" (MIDDELTON-MOZ; ZAWADSKI, 2007, p. 20).

Deste modo, o núcleo central das representações sociais dos acadêmicos do curso de Pedagogia sobre o que o bullying pode causar em suas vítimas corrobora em parte com a literatura sobre o assunto, deixando claro que este fenômeno se tornou objeto social que perpassa o senso comum e o conhecimento científico.

Embora esse quadro demonstre que o grupo 'Isolamento' ( $2^{\circ}$ quadrante) não seja pertencente ao núcleo central, a alta frequência de evocações (25) e sua OME de 2,02, muito próximo ao limite que o classificaria no $1^{\circ}$ quadrante $(2,01)$, faznos considerá-lo como possível elemento nuclear. Estão também no $2^{\circ}$ quadrante os 'Transtornos de ansiedade' como as fobias, os medos, a síndrome do pânico e a ansiedade, que foram bastante evocados, tendo uma frequência de 25 , no entanto o OME é de 2,32, ou seja, não foram prontamente evocadas.

No $3^{\circ}$ quadrante há seis grupos distintos com frequências que variam de 12 a 2, entre esses grupos estão os 'Transtornos psicológicos' e os 'Problemas escolares', caracterizados pelo baixo desempenho escolar e pela desistência dos estudos.

Ressalta-se que, muitas vezes, o próprio professor pode ser o algoz de seu aluno, pois a forma como ele representa seus alunos, seja por meio da linguagem, atitudes, observações ou comentários feitos em sala de aula, pode afetar a aprendizagem e as representações que o aluno tem sobre si mesmo. Se, em seu discurso, o professor sugerir ou afirmar que certas crianças são incapazes de aprender, mesmo que se esforcem, elas poderão acreditar que são incapazes e impotentes. Consequentemente, o fracasso produz a internalização de uma autoimagem negativa (SIRINO, 2002).

Ostti e Brenelli (2013) ressaltam que os alunos com dificuldades não possuem representações positivas de si mesmos, porque não aprendem e por estar 
em defasagem em relação aos conteúdos; assim, essas representações de si mesmos apontam para o valor afetivo envolvido no processo de ensino e aprendizagem, visto que a afetividade é uma forma de força que impulsiona e atribui valor às atividades e constitui valor de influência para a aprendizagem e para a construção de novos conhecimentos.

De acordo com Osti (2012), as representações podem promover ou até mesmo impedir o avanço cognitivo do aluno, uma vez que o aluno com dificuldades também apresenta sentimentos como insegurança, baixa autoestima, medo, dentre outras variáveis que interferem no processo de aprendizagem dele.

Os elementos que aparecem no $4^{\circ}$ quadrante são a 'Tristeza', com frequência 12 e OME de 2,08; a 'Vergonha', sentimentos que as vítimas têm ao ser alvo de chacotas, piadas e ridicularizações, com uma baixa frequência (7); os 'Transtornos alimentares', como anorexia, bulimia ou obesidade também com frequência baixa (4); as 'Doenças' e o 'Uso de substâncias' como álcool e drogas, ambas com frequência baixa ( 4 e 2 , respectivamente).

Por meio da análise do Quadros 2, foi possível verificar que as RS dos participantes da pesquisa acerca das consequências de bullying para a vítima são a depressão, a morte por suicídio ou assassinato, a desvalorização de si mesma, o isolamento e outros transtornos, corroborando as pesquisas acerca do assunto.

\section{CONSIDERAÇÕES FINAIS}

Ao iniciar a pesquisa, percebeu-se que o bullying escolar é um tema bastante recorrente em diversas áreas de estudo, no entanto, ao estreitar o tema e buscar as representações sociais acerca do bullying, o número de pesquisa diminuiu consideravelmente. Estreitou-se ainda mais a busca e se procurou as representações sociais de acadêmicos do curso de Pedagogia relativas ao assunto e nada foi encontrado. Desta forma, foram investigadas as representações sociais de acadêmicos do curso de Pedagogia de uma universidade pública, futuros professores, a fim de se distinguir os significados que eles atribuem ao bullying, bem como identificar o núcleo central e periférico dessas representações. 
Para discernir os conhecimentos socialmente elaborados pelo grupo de acadêmicos de um curso de Pedagogia referentes ao bullying, foi utilizada a Teoria das Representações Sociais, por ser uma construção ontológica, epistemológica, psicológica, social, cultural e histórica.

Jovchelovitch (2004) assinala que esse processo é ontológico, pois tem um papel constitutivo do sujeito como ser que representa a si mesmo e que possui identidade. É epistemológico, porque permite o (re)conhecimento do saber sobre o objeto (Eu, Outro, objeto-mundo). É um processo psicológico, porque se estrutura e se manifesta como processo psíquico suscetível aos artifícios da paixão, da ilusão e do desejo. É um processo social, pois o subjetivo ocorre à luz da história e da cultura e o seu status polivalente reafirma a sua estrutura mediadora.

Constatou-se, por meio dessa pesquisa, que as Representações Sociais dos acadêmicos do curso de Pedagogia, acerca de bullying escolar, são formadas com base na mídia e no senso comum, o que sugere que este assunto permeia a sociedade e o cotidiano em que os participantes estão inseridos; fator que se confirma nas leis sancionadas nos anos de 2015 e 2016 no Brasil. A primeira a Lei 13.185 que institui o Programa de Combate à Intimidação Sistemática (bullying) e que entrou em vigor em fevereiro de 2016, pontua que é dever dos estabelecimentos de ensino, dos clubes, entre outros, assegurar medidas de conscientização, prevenção, diagnose e combate ao bullying.

Já, a segunda, a Lei 13.277, que entrou em vigor no dia 7 de abril de 2016, institui esse mesmo dia (7 de abril) como Dia Nacional de Combate ao Bullying e à Violência na Escola. A data foi escolhida por causa do conhecido massacre de Realengo. No dia 7 de abril de 2011, Wellington Menezes de Oliveira, de 23 anos, entrou na Escola Municipal Tasso da Silveira, no bairro de Realengo, na cidade do Rio de Janeiro, e disparou uma arma contra os estudantes. $\mathrm{O}$ ataque terminou com a morte de 12 alunos com idade entre 13 e 16 anos. O atirador cometeu suicídio na própria escola.

Os objetivos dessa pesquisa foram alcançados, uma vez que se conseguiu apreender como os participantes conceituam bullying, isto é, como uma forma de agressão (física, verbal ou moral) que se utiliza de maldade e crueldade com o intuito de desrespeitar, humilhar e excluir outros mais fracos. Quanto às 
representações sociais das consequências de bullying para as vítimas, constatou-se que a depressão, a morte por suicídio ou assassinato, a desvalorização quanto a si mesmo, o isolamento e outros transtornos estão no núcleo central da representação dos participantes.

É inegável o desejo de todos de que as escolas sejam ambientes seguros e saudáveis, nos quais crianças e adolescentes possam desenvolver o próprio potencial intelectual e social, mas, para isso, é necessário que tenhamos conhecimento e consciência sobre a gravidade desse fenômeno, que ainda apresenta estudos limitados; e que continuarão limitados, se os cursos de licenciatura, principalmente o curso de Pedagogia, não trouxerem essa temática para seu currículo, para discussão, pois, somente assim, os acadêmicos terão conhecimento acerca do assunto e buscarão respostas aos questionamentos por meio de projetos de pesquisa, ensino e extensão.

Os resultados do presente estudo, principalmente no âmbito escolar, devem nortear os esforços para se minimizar as ocorrências de bullying. Uma estratégia é que o tema seja inserido em disciplinas do curso de Pedagogia que discutam o processo de desenvolvimento e aprendizagem, pois esse fenômeno pode ser considerado um dos atuais geradores de problemas de aprendizagem, uma vez que afeta a estima da pessoa vitimizada, ou seja, as crianças e os adolescentes deixam de acreditar que são capazes de aprender e criam bloqueios para o próprio desenvolvimento e aprendizagem; em alguns casos, apresentam dificuldades de aprendizagem permanentes, se não diagnosticadas precocemente.

Destarte, por meio da reestruturação do curso de Pedagogia, podemos fazer esse tipo de violência deixar de ser invisível aos olhos dos professores, gestores e de toda a comunidade escolar, visto que, a partir de conhecimentos acerca desse fenômeno, os futuros professores podem contribuir e intervir de forma a prevenir e erradicar a práticas agressivas entre estudantes, mediando os conflitos nas escolas em busca de ambientes educacionais saudáveis e sem violência, promovendo, assim, a cultura da paz e do respeito ao próximo.

Como forma de intervenção, são necessárias ações pontuais como forma de prevenção e intervenção. Inicialmente, sugere-se a realização de palestras, cursos Workshops nas escolas, nas universidades e em centros de atendimento às crianças e 
adolescentes, bem como promover discussões acerca do assunto, com profissionais de outras áreas como Psicologia, Medicina, Enfermagem, Sociologia, entre outros, uma vez que este fenômeno é social e causa traumas físicos e psicológicos aos envolvidos.

Trabalhos em grupo é uma estratégia ideal para aproximar os pares, assim como desenvolvimento de atividades teatrais, visto que o teatro trabalha com o lúdico, que pode representar um meio de combater a agressividade, possibilitando à criança expressar simbolicamente o que foi reprimido, expor sentimentos acumulados de tensão, insegurança, frustração e agressividade, permitindo a conscientização de uma forma natural, fluente e sem culpa (CERRI, 2001 apud LUCON; SCHWARTZ, 2003).

A criança/adolescente que atua no teatro se torna um indivíduo criativo, possuindo senso de humor, sensibilidade estética e afetiva, intuição aguda, além de capacidade de empatia, isto é, sabe compreender o outro e se colocar na posição dele (REVERBEL, 1997). Do mesmo modo, faz a criança se autodescobrir, se autoconhecer e, assim, conseguir uma vida equilibrada.

Por fim, é importante sublinhar que a Teoria das Representações Sociais se mostra como um instrumento teórico-metodológico de grande utilidade para o estudo da atuação do imaginário social sobre o pensamento e as condutas de pessoas e grupos; no caso de nosso estudo, dos acadêmicos de um curso de Pedagogia.

Espera-se que esse estudo contribua para reconhecer as representações sociais dos futuros professores sobre o bullying. Todavia, para que essa conscientizaçao se efetive, é necessário que os cursos de formação de professores abarquem a referida temática e abram mais espaço para a pesquisa científica, pois o fenômeno do bullying é um assunto muito vasto e necessita de mais pesquisas que visem elucidar formas de prevenção e de tratamento no contexto escolar.

\section{REFERÊNCIAS}

ABRIC, J. C. A Abordagem Estrutural das Representações Sociais. In: MOREIRA, A.S.P.; OLIVEIRA, D.C. (Org.). Estudos Interdisciplinares de Representação Social. Goiânia: AB, 1998. p. 27-38. 
ABRIC, J. C. Las representaciones sociales: Aspectos Teóricos. In: ABRIC, J. C. (Org.). Práticas sociales y representaciones. Trad. José Dacosta Chevrel y Fátima Flores Palacíos: Coyoacán, México, 2001, p. 11-32.

ALMEIDA, L. S. LISBOA, C. Habilidades sociais e bullying: uma revisão sistemática. Contextos clínicos. São Leopoldo, v. 7, n. 1, p. 62-75, jan.jun. 2014

ALVES-MAZZOTTI, A. J. Representações Sociais: Aspectos Teóricos e Aplicações à Educação. Em Aberto, Brasília, v. 14, n. 61, p. 60-78, jan./mar. 1994. Disponível em: $<$ http://emaberto.inep.gov.br/index.php/emaberto/article/viewFile/1944/913>. Acesso em: 1 ago. 2015.

ANTUNES, D. C. Bullying: razão instrumental e preconceito. São Paulo. Casa do Psicólogo, 2010.

BEAUDOIN, M.; TAYLOR, M. Bullying e desrespeito: como acabar com essa cultura na escola. Tradução: Sandra Regina Netz. Porto Alegre: Artmed, 2006.

BINSFELD, A. R.; LISBOA, C. S. M. Bullying: um estudo sobre papéis sociais, ansiedade e depressão no contexto escolar do Sul do Brasil. Interpersona: an International Journal on Personal Relationships, v. 4, n. 1, p. 74-105, 2010.

BRASIL, Ministério da Educação. Lei 13.277/16. Institui o dia 7 de abril como Dia Nacional de Combate ao Bullying e à Violência na Escola. Diário Oficial da União, Brasília, 2 de maio de 2016, Seção 1, p. 3.

BRASIL, Ministério da Educação; Ministério das Mulheres e Igualdade Racial e dos Direitos Humanos. Lei 13.185/15. Institui o Programa de Combate à Intimidação Sistemática (BULLYING). Diário Oficial da União, Braślia, 9 de novembro de 2015, Seção 1, p. 1. Disponível em: < http://www.planalto.gov.br/ccivil_03/_Ato20152018/2015/Lei/L13185.htm. > Acesso em: 23 fev. de 2016.

CARDOSO, C. F. O uso, em história, da noção de representação social desenvolvida na psicologia social: um recurso metodológico possível. Revista Psicologia e Saber Social, Rio de Janeiro, v. 1 n. 1, 2012, p. 40-52. Retirado de: <www.e-publicacoes. 
uerj.br/index.php/psi-sabersocial/article/download/3244/2262> Acesso em: 30 de jul. 2015.

CONSTANTINI, A. Bullying: Como combatê-lo? Prevenir e enfrentar a violência entre jovens. Tradução: Eugênio Vinci de Moraes. São Paulo: Itália Nova, 2004.

CORTES JUNIOR, L. P. As Representações Sociais de "Química Ambiental": contribuições para a formação de bacharéis e professores de Química. São Paulo, 2008. Dissertação ( Mestrado) - Instituto de Química, Física e Biociência e Faculdade de Educação, da Universidade de São Paulo, SP.

CORTES JUNIOR, L. P.; FERNANDEZ, C. A Educação Ambiental na formação de professores de Química: Estudo diagnóstico e Representações Sociais. Revista Química Nova, São Paulo, v. 39, n. 6, p. 748-756, jul. 2016. Disponível em: < http:// www.scielo.br/pdf/qn/v39n6/0100-4042-qn-39-06-0748.pdf> Acesso em: 02 ago. 2016.

COUTINHO, K. A. Bullying e dificuldades de aprendizagem: consequências de uma violência velada. 2013. 47f. Monografia (Especialização em Psicopedagogia Clínica e Institucional) - Universidade Estadual de Maringá, PR.

COUTINHO, K. A. As Representações Sociais de acadêmicos do curso de Pedagogia acerca de bullying. 2017. 212f. Dissertação (Mestrado em Educação) Universidade Estadual de Maringá, PR.

ENZ, R. T.; EYNG, A. M.; GISI, M. L. Representações Sociais sobre bullying no cotidiano das escolas públicas de Educação básica. Revista de Educação Pública, Cuiabá, v. 22, n. 50, p. 785-808, 2013.

FANTE, C. Fenômeno bullying: como prevenir a violência nas escolas e educar para a paz. Campinas: Verus, 2005.

FANTE, C.; PEDRA, J. A. Bullying escolar: perguntas e respostas. Porto Alegre: Artmed, 2008. 
JODELET, D. La Representation Social: Fenômenos, Concepto y Teoría. In: MOSCOVICI, S. (Org.). Psicologia Social. Barcelona: Paidós, 1984. p. 469-494.

JOVCHELOVITCH, S. Os contextos do saber: representações, comunidade e cultura. Trad. Pedrinho Guareschi. 2. ed. Petrópolis: Vozes, 2011.

JOVCHELOVITCH, S. Representações sociais: para uma fenomenologia dos saberes Sociais. Revista Psicologia \& Sociedade, v. 10, n. 1, p. 54-68; jan./ jun.1998. Disponível em: < abrapso.org.br/...images/...P_e_S_volume\%20_10_ numero_1_1998.do.. >. Acesso em: 20 abr. de 2016

JOVCHELOVITCH, S. Vivendo a vida com os outros: intersubjetividade, espaço público e Representações Sociais. In: GUARESCHI, P.; JOVICHELOVTCH, S. (Org.) Textos em Representaçóes Sociais. 14. ed. Petrópolis: Vozes, 2013, p. 53-72.

JOVChelovitCH, S. Psicologia Social, Saber e Cultura. Revista Psicologia \& Sociedade, v. 16, n. 2, p. 20-31, maio/ago.2004 Disponível em: <http://www.scielo. br/pdf/psoc/v16n2/a04v16n2.pdf> . Acesso em: 14 abr. 2016.

LEMOS, A. C. M. Uma Visão Psicopedagógica do bullying escolar. Revista Psicopedagogia, 24(73), 2007, pp. 68-75.

LISBOA, C.; BRAGA, L. L.; EBERT, G. O Fenômeno bullying ou Vitimização entre pares na atualidade: definições, formas de manifestação e possibilidades de intervenção. São Leopoldo, RS, 2009. Disponível em: < http://www.contextosclinicos. unisinos.br/pdf/61.pdf > . Acesso em: 29 jan. 2016.

LOPES NETO, A. A. Bullying: comportamento agressivo entre estudantes. Jornal de Pediatria, Rio de Janeiro v. 81, n. 5. p. 164-172, 2005. Disponível em: < http://www. observatoriodainfancia.com.br/IMG/pdf/doc-158.pdf>. Acesso em: 18 jan. 2016.

LYRA, L. R.; BAUMER, G. C. Bullying e filhos de presidiários no Ensino fundamental: algumas reflexões. Colóquio Internacional de Educação e Seminário sobre Indicadores de Qualidade do ensino fundamental, v. 1, p. 609-618, 2011. 
MAGALHÃES JÚNIOR, C. A. O.; TOMANIK, E. A. Representações sociais e direcionamento para a educação ambiental na Reserva Biológica das Perobas, Paraná. Investigações em Ensino de Ciências, Porto Alegre, v. 17, n. 1, p. 227-248, 2012.

MAGALHÃES JÚNIOR, C. A. O.; TOMANIK, E. A. Representações sociais de subsídios para a formação continuada de professores. Ciências e Educação, Bauru, v. 19, n. 1, p. 181-199, 2013.

MENIN, M. S. S.; SHIMIZU, A. M.; LIMA, C. M. A Teoria das Representações Sociais nos estudo sobre representações de professores. Cadernos de Pesquisa, v. 39, n. 137, maio/ago. 2009. Disponível em: < http://www.scielo.br/pdf/cp/v39n137/ v39n137a11.pdf > . Acesso em: 05 ago. 2015.

MIDDELTOM-MOZ, J.; ZAWADSKI, M. L. Bullying: estratégias de sobrevivência para crianças e adultos. Tradução: Roberto Cataldo Costa. Porto Alegre: Artmed, 2007.

MINAYO, M. C. S. A Violência Social sob a Perspectiva da Saúde Pública. Cadernos de Saúde Pública. Rio de Janeiro, v. 10, (supl. 1), p. 7-18, 1994. Disponível em: $<$ http://www.scielo.br/pdf/csp/v10s1/v10supl1a02 > . Acesso em: 01 out. 2017.

MOSCOVICI, Serge. A Psicanálise, sua imagem e seu público. Trad. Sonia Fuhrmann. Petrópolis: Vozes, 2012.

MOSCOVICI, Serge. Representações Sociais: investigações em Psicologia Social. Trad. Pedrinho A. Guareschi. 11. ed. Petrópolis, RJ: Vozes, 2015.

NAIFF, D. G. M. NAIFF, L. A. M. SOUZA, M. A. As Representações sociais de estudantes universitários a respeito das cotas para negros e pardos nas universidades públicas brasileiras. Estudos e Pesquisas em Psicologia, Rio de Janeiro, v. 9, n. 1, p. 216229, 2009. Disponível em:<http://www.revispsi.uerj.br/v9n1/artigos/pdf/v9n1a17. pdf $>$. Acesso em: 10 jun. 2016.

OLIVEIRA, D. C.; FISCHER, F. M.; TEIXEIRA, M. C. T. V.; SÁ, C. P.; GOMES, A. M. T. Representações sociais do trabalho: uma análise comparativa entre jovens trabalhadores e não trabalhadores. Ciências e Saúde Coletiva, Rio de Janeiro, v. 
15, n. 3 p. $763-773,2010$.

OSTI, A. Dificuldade de Aprendizagem, Afetividade e Representações sociais. Jundiaí, SP: Paco, 2012.

OSTI, A. BRENELLI, R. P. Sentimentos de quem fracassa na escola: análise das representações de alunos com dificuldades de aprendizagem. Revista Psico-USF, Bragança Paulista, v. 18, n. 3, p. 417-426, set./dez. 2013.

PEREIRA, B. O. Para uma escola sem violência: estudo e prevenção das práticas agressivas entre crianças. Fundação Calouste Gulbenkian; Fundação para a Ciência e a Tecnologia: Porto, 2002.

PULLIN, E. M. P.; PRYJMA, L. C. Representações sociais da leitura: núcleo central e periferia dessas representações entre professores. Práxis Educativa, Ponta Grossa, v. 6 , n. 2, 2011, p. 207-222.

REVERBEL, O. Um caminho do teatro na escola. 2. ed. São Paulo: Scipione, 1997. (Coleção Pensamento e ação no Magistério).

ROCHA, Z. Ética, cultura e crise ética de nossos dias. Síntese, Belo Horizonte, v. 34 , n. 108 , p. $115-131,2007$.

SÁ, C. P. A Construção do Objeto de Pesquisa em Representações Sociais. Rio de Janeiro: EdUERJ, 1998.

SÁ, C. P. Núcleo Central das Representações Sociais. 2. ed. Petrópolis: Vozes, 2002.

SIRINO, M. F. Repensando o fracasso escolar: reflexões a partir do discurso da criança-aluno. 2002. 253f. Dissertação (Mestrado) - Universidade Estadual Paulista, Assis, SP.

SPINK, M. J. P. O estudo empírico das Representações Sociais. In: SPINK, M. J. O conhecimento no cotidiano: as representações sociais na perspectiva da Psicologia social. São Paulo: Brasiliense, 1993. p. 85-108. 
WEISS, M. L. L. Psicopedagogia Clínica: uma visão diagnóstica dos problemas de aprendizagem escolar. Rio de Janeiro: DP\&A, 1997.

Recebido em: 30 de julbo de 2017.

Aceito em: 04 de outubro de 2017. 